\title{
RISCO NO TRABALHO: A FORMAÇÃO DA IDENTIDADE DOS ELETRICISTAS
}

\author{
RISK AT WORK: IDENTITY FORMATION \\ OFELECTRICIANS
}

Julice Salvagni ${ }^{1}$

\section{RESUMO}

Este estudo busca compreender a formação da identidade dos trabalhadores do setor elétrico, os quais convivem constantemente com alto risco de acidentes de trabalho. Percorremos, para tanto, a noção de identificação e identidade, centralmente embasadas por Hall e Goffman. Também buscamos entender o risco específico do setor elétrico e o conceito de masculinidade de Bourdieu como um aspecto importante para embargar a discussão. Por fim, tratamos do conceito de Segurança Ontológica, abordado por Giddens, por meio do que levantamos a importância da visibilidade do risco através da passagem discursiva, que permite aos trabalhadores um espaço para a tomada de consciência do risco e a possibilidade de criarem formas mais seguras de trabalho.

Palavras-chave: Identidade. Trabalho. Masculinidade. Risco Invisível. Segurança ontological.

\footnotetext{
1 Mestranda em Ciências Sociais (UNISINOS); Especialista em Gestão Empreendedora (FTEC); Psicóloga Clínica e do Trabalho.E-mail: julices@terra.com.br
} 


\begin{abstract}
This study seeks to understand the identity formation of the electric sector workers, who live constantly with high risk of accidents. We have come to this end, the notion of identification and identity, centrally grounded by Hall and Goffman. We also seek to understand the specific risk of the electricity sector and the concept of masculinity by Bourdieu as an important aspect to withhold the discussion. Finally, we treat the concept of ontological security, discussed by Giddens, where we raise the importance of visibility of risk by shifting discursive, allowing workers to a space for awareness of risk and opportunity of developing safer ways of working.
\end{abstract}

Keywords: Identity. Work. Masculinity. Invisible Risk. Ontological security.

\title{
APRESENTAÇÃO
}

A fim de compreendermos como é o trabalho dos homens que lidam constantemente sob risco de acidente - especialmente trabalhadores do setor elétrico -, percorremos a literatura que nos possibilita refletir sobre a identidade destes trabalhadores. Interessa-nos conhecer como é trabalhar em contato com o risco constante de um acidente fatal e de que forma este trabalho implica na composição da identidade de tais trabalhadores.

Inicialmente, para a compreensão da realidade em foco, o trabalho faz uma discussão entre identificação e identidade, constituídas socialmente e através do discurso. Hall é o autor central da discussão, muito embora o conceito se desdobre para outras linhas de pensamento, como a construção dos autores sociais de Goffman.

O estudo segue com a reflexão do masculino, proposta por Pierre Bourdieu, enquanto elemento fundamental para um entendimento mais amplo da questão. $\mathrm{O}$ autor desenvolve a temática da dominação masculina também pelo viés da divisão do trabalho.

Em se tratando do risco, este pode também ser visto como uma maneira de enaltecer a virilidade do homem, trazendo ao trabalhador certo tipo de gozo advindo do trabalho perigoso, ou da atividade não realizada pela mulher. Ora, nisso também se pode relacionar a aparente despreocupação do trabalhador com o uso do equipamento individual de segurança, denotando uma necessidade de os homens se manterem ilusoriamente mais fortes por serem capazes de enfrentar o risco "de corpo aberto", atitude muito comum entre trabalhadores do setor.

Ainda, desenvolvemos o conceito de segurança ontológica proposto por Anthony Giddens, por meio do qual ele discute a segurança com base na psicologia - em se tratando de uma segurança primária e constituída no início da vida - para dar conta dos elementos da segurança que são fundamentais à formação das identidades. A teoria em questão aparecerá articulada no artigo com autores que pensam a segurança na área do trabalho, especificamente, no intuito de provocar uma discussão entre os modos de conceber o conceito.

A compreensão da dominação do masculino articulada com o entendimento de uma segurança ontológica, ambas desenvolvidas à luz de conceitos do trabalho, permitem compreendermos elementos centrais na formação da identidade dos homens do setor elétrico. Estudos mais específicos à área são de fundamental importância, tendo em vista a necessidade de fomentar intervenções junto ao setor, ainda muito despreparado para lidar com risco enquanto uma rotina de trabalho. 


\section{IDENTIFICAÇÃO E IDENTIDADE}

Para Hall (2000), o conceito de identificação é pouco desenvolvido pelas ciências sociais, sendo necessário importar conceitos da psicanálise para estabelecer uma compreensão. $O$ autor propõe a identificação como "uma construção, como um processo nunca completado - como algo sempre 'em processo'” (HALL, 2000, p. 106).

Ao contrário do que se estabelece no senso comum - a identificação como o reconhecimento de iguais -, a identificação

[...] opera por meio da différance, ela envolve um trabalho discursivo, o fechamento e a marcação de fronteiras simbólicas, a produção de 'efeitos de fronteira'. Para consolidar o processo ela requer aquilo que é deixado de fora - o exterior a constitui (HALL, 2000, p. 106, grifo nosso).

Tal entendimento faz com que a produção de identificações não seja algo lógico e determinado. As identificações podem ir de encontro à identidade do sujeito, ou diferenciarem-se por completo. Neste jogo de reconhecimento é que a identidade vai se criando.

Assim, este processo de identificação, ou de diferenciação, é fundamental para a compreensão da formação das identidades. A identidade será coletivamente constituída por essas identificações, através do discurso, muito embora o ego ideal seja "composto de identificações com ideais culturais que não são necessariamente harmoniosos" (HALL, 2000, p. 107).

Hall entende que

[...] as identidades não são nunca unificadas; que elas são, na modernidade tardia, cada vez mais fragmentadas e fraturadas; que elas não são nunca singulares, mas multiplamente construídas ao longo do discurso, práticas e posições que podem se cruzar ou ser antagônicas. As identidades são sujeitadas a uma historicização radical, estando constantemente em processo de mudança e transformação (HALL, 2000, p. 108, grifos nossos).

Buscamos, neste estudo, a análise do risco invisível presente em muitos trabalhos, como forma central ao entendimento da formação das identidades dos trabalhadores, e compreendendo, inclusive, que "as identidades surgem, esteja, em parte, no imaginário (assim como no simbólico) e, portanto, sempre, em parte, construída na fantasia ou, ao menos, no interior de um campo fantasmático" (HALL, 2000, p. 109). Há, dessa forma, um conteúdo simbólico fundamental para o entendimento do que entendemos como o processo de formação identitária.

Por esta concepção, o estudo da identidade presume uma observação apurada do social e do meio onde a pessoa está inserida como um espaço produtor de material simbólico. Neste caso, consideramos o trabalho uma fonte fundamental para a produção das identidades.

Veronese e Esteves (2009) destacam que, "na esfera da intersubjetividade produzida pelo trabalho, vivências e aprendizagens incorporam-se à dimensão identitária dos sujeitos em interação", sendo fundamental uma leitura das formas de trabalho para que seja possível compreender a formação identitária dos sujeitos em foco, em especial, na relação com o trabalho vinculado ao risco invisível. 
Goffman (1985) vai tratar da identidade dos sujeitos mais no sentido de atores sociais que desempenham um papel. Esses atores sociais representam papéis que vão fazer sentido no coletivo, sendo a representação entendida pelo autor como

[...] toda a atividade de um indivíduo que se passa num período caracterizado por sua presença contínua diante de um grupo particular de observadores e que tem sobre estes alguma influência. Será conveniente denominar de fachada à parte do desempenho do indivíduo que funciona regularmente de forma geral e fixa com o fim de definir a situação para os que observam a representação (GOFFMAN, 1985, p. 29).

O local de trabalho é um espaço importante para a formação das representações definidas por Goffman. Os observadores podem ser pensados como os colegas de trabalho que ajudam a compor a representação do ator no mesmo jogo que já descrevemos como identificação e que, da mesma forma, vai compondo a identidade. Assim como no jogo de identificações, "se um indivíduo tem de dar expressões a padrões ideais na representação, então terá de abandonar ou esconder ações que não sejam compatíveis com eles" (GOFFMAN, 1985, p. 46).

Esta identidade, de certo modo, vai representar uma verdade para quem a vivencia e será sempre uma construção coletiva, além de individual. "Quando um ator assume um papel social estabelecido, geralmente verifica que uma determinada fachada já foi estabelecida para este papel" (GOFFMAN, 1985, p. 34). Esta fachada é a construção coletiva que permite aos autores sociais se constituírem.

Pensando no setor elétrico, há muitas especificidades da área que constituem a identidade coletiva que tanto referimos na literatura. Para compreendermos as especificidades do que colocamos como risco, é preciso, antes da discussão teórica, revisarmos as características do trabalho dos eletricitários.

\subsection{Setor elétrico}

As articulações empíricas com a teoria surgem a partir de um trabalho que está sendo realizado junto com o setor elétrico, de montagem de redes. Os sujeitos convivem com inúmeros riscos que vão desde os choques elétricos até muitas outras adversidades presentes no campo de trabalho. Um estudo dos eletricitários de São Paulo indica que o trabalho

[...] é caracterizado pela presença de demandas físicas e mentais importantes, sendo que os riscos à saúde e segurança dos trabalhadores são considerados elevados, co-existindo riscos de origem elétrica (choque elétrico e exposição a campos eletromagnéticos), mecânicos (quedas e acidentes de trânsito), biológicos (ataques de animais e contaminação biológica), químicos (contaminantes em ambientes fechados), físicos (ruído, calor, frio e chuva), biomecânicos (movimentação e posturas inadequadas, transporte de cargas) e psicossociais (pressão de prazos e de responsabilidades, volume de trabalho, solução de problemas e tomada de decisões, necessidade de adaptação a novas tecnologias, pressão de chefias e de clientes) (MARTINEZ; LATORRE, 2008, p. 03, grifo nosso). 
Para além destes riscos, podemos incluir outros mais sutis, mas não menos preocupantes, que são comuns às demais profissões, como medo de ser demitido, de errar, de ser motivo de deboche entre colegas, etc. Todas essas situações constituem o que entendemos por risco invisível presente nas relações de trabalho, provocador de sofrimento psíquico.

O grupo de trabalhadores em foco é constituído essencialmente por homens, sendo fundamental discutirmos o porquê de os homens ainda dominarem o setor elétrico. A masculinidade está diretamente relacionada com as questões de risco e identidade, sendo, desse modo, importante descrevermos as particularidades do masculino como pano de fundo para a atividade laboral.

\section{O MASCULINO E O TRABALHO}

Trago à discussão uma teorização sobre a masculinidade, não só pelo fato de os homens serem a esmagadora maioria entre os que trabalham no setor elétrico, mas também por serem notáveis as afirmações da masculinidade em virtude do trabalho ligado ao risco.

É importante destacar, no entanto, que a relação da masculinidade com o risco é apenas um dos aspectos importantes a ser estudado. Existem outras tantas variáveis, não menos importantes, mas que serão aprofundados em outros estudos.

Embora as questões acerca do gênero venham mudando ao longo do tempo, "a diferença anatômica entre os órgãos sexuais pode assim ser vista como justificativa natural da diferença socialmente constituída entre os gêneros e, principalmente, da divisão social do trabalho" (BOURDIEU, 2003, p. 20).

O trabalho passou a ser socialmente construído, juntamente com outros tantos aspectos da humanidade e paralelamente à dominação do masculino, ditando formas diferentes de trabalhos para homens e mulheres. $O$ fato de as mulheres ficarem em casa para cuidar dos filhos e, em contrapartida, de os homens dedicarem-se ao trabalho foi marcando socialmente o gênero da dominação. Assim,

[...] a divisão das coisas e das atividades (sexuais e outras) segundo a oposição entre o masculino e o feminino recebeu a necessidade objetiva e subjetiva de sua inserção em um sistema de oposições homólogas, alto/baixo, em cima/embaixo, na frente/atrás, direita/esquerda [...]. Semelhantes na diferença, tais oposições são suficientes concordes para se sustentarem mutuamente, no jogo e pelo jogo inesgotável de transferências práticas e metáforas; e também suficientemente divergentes para conferir, em cada uma, uma espécie de espessura semântica, nascida da sobredeterminação pelas harmonias, conotações e correspondências (BOURDIEU, 2003, p. 16, grifo nosso).

Esse sistema de oposições descrito por Bourdieu vai fazer com que o trabalho braçal, por exemplo, seja marcado pela virilidade do homem, enquanto às mulheres vão restar os trabalhos mais leves e menos reconhecidos. Pensando nos trabalhos que envolvem riscos, pode-se considerar de imediato a organização de um tipo de trabalho ainda essencialmente marcado pelo masculino, o que de fato acontece.

No que tange à formação da identidade masculina, é mais fácil para o homem estar à frente de uma função considerada superior, de dominação, do que ocupando algum cargo já exercido ou caracterizado pela presença feminina. Ocupar cargos ou estar em situações comuns 
à mulher pode fazer com que o homem perca automaticamente o seu lugar de cominação; por isso, o gozo do trabalho com o risco como algo importante na formação identitária.

Sobre a relação histórica e socialmente construída de dominação, entendemos que a diferenciação é algo fundamental para a consolidação de uma identidade viril.

Se a relação sexual se mostra como uma relação social de dominação, é porque ela está construída através do princípio de divisão fundamental entre o masculino, ativo, e o feminino, passivo, e porque este princípio cria, organiza, expressa e dirige o desejo - o desejo masculino como desejo de posse, como dominação erotizada, e o desejo feminino como um desejo da dominação masculina, como subordinação erotizada, ou mesmo, em última instância, como reconhecimento erotizado da dominação (BOURDIEU, 2003, p. 31, grifo nosso).

Por esta concepção, trabalhar com o risco também é estar garantindo uma posição de gozo e garantia de dominação identitária masculina. Isso fica visível na fala dos trabalhadores do setor elétrico, que se mostram descontentes por atuarem em algo sujo, pesado e que envolve tantos riscos. Ao mesmo tempo, porém, eles discursam orgulhosos por serem os únicos entre muitos capazes de fazer tal atividade. Esta é também uma maneira de manter sua virilidade em épocas nas quais as mulheres já ocupam muitos cargos de trabalho que, antes da revolução feminista, eram impensados como possíveis a elas.

O autor entende como virilidade "uma noção eminentemente relacional, construída diante dos outros homens, para os outros homens e contra a feminilidade, por uma espécie de medo do feminino, e construída, primeiramente, dentro de si" (BOURDIEU, 2003, p. 67), o que vai de encontro com a formação da identidade - até porque uma está presente na outra e ambas se compõem mutuamente -, especialmente pela lógica da diferenciação como constituição identitária primeira.

Este enaltecimento da identidade ligado à virilidade também pode ser relacionado com a negação do risco pelos trabalhadores - além da negação do risco pelo próprio risco, como veremos na discussão do próximo capítulo -, já que pela constituição hierárquica de dominação dos gêneros "a pior humilhação, para um homem, consiste em ser transformado em mulher" (BOURDIEU, 2003, p. 32). Encarar o risco "de corpo aberto" ou sem os equipamentos de segurança necessários pode ser considerada uma maneira de garantir esta virilidade masculina pelo trabaIho.

Além disso, o maior risco é justamente quando se ignora o risco como forma de defesa, sendo mais perigoso para os trabalhadores a negação de uma situação de risco que a preocupação propriamente sobre este risco.

Para o autor, este posicionamento sugere a manutenção do ponto de honra que é um sistema de estratégias de reprodução pelas quais

[...] os homens, detentores do monopólio dos instrumentos de produção e de reprodução do capital simbólico, visam a assegurar a conservação ou o aumento deste capital: estratégias de fecundidade, estratégias matrimoniais, estratégias educativas, estratégias econômicas, estratégias de sucessão, todas elas orientadas no sentido de transmissão dos poderes e privilégios herdados (BOURDIEU, 2003, p. 62). 
A manutenção dos postos de trabalho ligados diretamente à produção, especialmente os que exigem maior aperfeiçoamento e cuidado, garantem de alguma forma a posição da identidade do homem neste local de poder e dominação.

Gastaldo, em um artigo que escreveu tratando da teoria de Goffman, entende que a relação de poder "existe na medida em que algumas definições da situação são mais legítimas do que outras, e essa legitimidade é a resultante de quem tem o poder de propor e sustentar a definição" (2008, p. 150). Em se tratando do setor elétrico, tal posição de poder sobre a condição de trabalho é sustentada a fim de tornar a profissão mais legítima no entendimento dos próprios sujeitos atuantes no setor.

Aqui, o risco acaba vindo de encontro à permanência de legitimidade do poder, na medida em que sustenta a profissão na virilidade masculina e dominante construída. Essa constatação pode ser vista de forma positiva, já que garante uma identidade profissional ao sujeito bem definida e fortalecida; por outro lado, o gozo no enfrentamento do risco para a manutenção de tal identidade vai se apresentar como um risco ainda maior.

Não raro, observamos trabalhadores desafiando o risco como forma de sustentar sua própria identidade, de pôr-se à prova. Em contato com trabalhadores do setor, o risco chega a ser exaltado no sentido de sustentar esta identidade viril, muitas vezes sendo tratado como algo que não prejudica a segurança do trabalhador. O risco, assim, é apenas usado como objeto de identificação.

\section{SEGURANÇA ONTOLÓGICA}

Giddens (2002) faz uma reflexão acerca da segurança ontológica, percorrendo a noção de risco no sentido amplo, ou seja, que pode ser aplicada a diversas situações. O autor recorre à psicanálise da infância para compreender os processos de estruturação da identidade, o que é fundamental para a subjetividade do sujeito adulto. Para ele, "a manutenção da vida, nos sentidos corporal e da saúde psicológica, está inerentemente sujeita ao risco" (GIDDENS, 2002, p. 43).

A fim de melhor explicar a origem da concepção de risco invisível presente em situações de trabalho, o autor descreve a criação da confiança básica do seguinte modo:

[...] a criança, em circunstâncias normais, investe nos que cuidam dela argumento - pode ser vista como uma espécie de inoculação emocional contra ansiedades existenciais - uma proteção contra ameaças e perigos futuros que permite que o indivíduo mantenha a esperança e coragem diante de quaisquer circunstâncias debilitantes que venha a encontrar mais tarde. A confiança básica é um dispositivo de triagem em relação a riscos e perigos que cercam a ação e a interação. É o principal suporte emocional de uma carapaça defensiva ou casulo protetor que todos os indivíduos normais carregam como meio de prosseguir com os assuntos cotidianos (GIDDENS, 2002, p. 43, grifo nosso).

O processo de desenvolvimento da confiança básica no início da vida pode ser uma marca essencial da noção de segurança para a vida adulta. O que o autor entende por "indivíduos normais" são justamente aqueles que produzem este vínculo inicial de segurança com o cuidador, vínculo este essencial para a manutenção de uma identidade estruturada do adulto.

O conceito de confiança básica inicial pode ser entendido, mesmo que usado para descrever uma cena inicial da infância, nas mais diversas formas sociais, como é o caso do trabalho. 
Se os trabalhadores tiveram um vínculo de confiança com uma empresa que se mostra preocupada com o bem-estar do funcionário, por exemplo, cedendo equipamentos de proteção individual e estimulando o uso e a importância dos mesmos, já estaria sendo proporcionada, seguindo a lógica de Giddens, a noção da segurança ontológica.

Para a psicanálise, a vivência da ausência, ou do risco, e a superação desta na fase inicial da vida, principalmente, é o que vai ser fundamental para a construção de uma identidade segura. Ora, pensando no ambiente empresarial, a vivência deste risco e não a omissão dele é que vai ser importante para a formação de sujeitos mais seguros para atuarem em uma atividade tão perigosa.

O autor entende a confiança como "o modo de lidar com as ausências de tempo e espaço implicadas na abertura do espaço potencial" (GIDDENS, 2002, p. 45). Suportar estas ausências é o que vai proporcionar uma vida mais segura, com menos medos e ansiedades. Nada mais é do que a simbologia de uma função materna que vai e volta, dando a segurança ao bebê de que as ausências podem ser sentidas e suportadas.

Voltando a lógica como representação ao nosso estudo junto ao trabalho, percebemos que as empresas, assim como a função materna, também têm o dever de provocar situações que permitam ao trabalhador criar um ambiente de segurança no trabalho. Para tanto, o risco deve ser reconhecido, nomeado e tratado às claras pela empresa com os funcionários.

No trabalho de campo com eletricitários, eles descrevem empresas onde o trabalho de alto risco é imposto ao funcionário, sob pena se perder o emprego caso esse risco seja negado. Além do toda a tensão de exercer um trabalho sem segurança, sabendo que se está correndo risco de vida, os funcionários relatam muita ansiedade justamente pelo fato de a empresa não tratar do risco.

Quando o risco é invisível para a empresa, ele é negado e os funcionários são obrigados a exporem-se frente a situações perigosas, o que cria proporções gigantes no imaginário dos funcionários, que, além de tudo, não recebem assistência alguma para o controle deste tipo de ansiedade. Por isso, a importância de um espaço de escuta por parte das empresas, em especial naquelas que trabalham com atividades que envolvem alto risco.

A passagem discursiva do risco - invisível para visível - é essencial na produção da segurança ontológica e na consequente diminuição da ansiedade dos funcionários. Diminuindo a ansiedade também se reduz o sofrimento psíquico e, consequentemente, alguns riscos.

Giddens vai entender como invisível "o que não pode ser posto em palavras" (2002, p. 45) - sendo os intercâmbios com pessoas e objetos ao nível da prática diária -, o que vai constituir a condição necessária do que pode ser dito, dos significados envolvidos na consciência prática. Assim, o trabalho de tornar o invisível algo visível se dá na prática discursiva, possibilitando a tomada de sentido e a produção de significados.

Podemos entender este trabalho de tornar o risco invisível em algo visível, ou dizível, como a condição necessária para a elaboração do sofrimento psíquico. Algo que fica na ordem do invisível - e, portanto, indizível - vai ser o grande produtor da ansiedade e da falta de segurança ontológica.

Em termos práticos, quando acontece um acidente de trabalho, seja na empresa dos trabalhadores, seja em outro local do mesmo ramo, os trabalhadores se dizem mais conscientes da importância de uma atividade segura. Esta tomada de consciência nada mais é do que a visibilidade de um risco que sempre esteve ali, embora não muito visível.

Para que esta tomada de consciência não aconteça apenas depois de algum acidente, é importante que a empresa desempenhe o seu papel de transmissora do conhecimento do risco em si aos trabalhadores, no formato de treinamentos constantes para que eles percorram as 
dimensões do risco. Desta forma, além de melhor preparar o funcionário para a atividade, este poderá sentir-se mais seguro, já que reconhece os riscos e as maneiras de evitar acidentes de trabalho.

De qualquer modo, Giddens considera que

[...] todos os indivíduos desenvolvem um referencial de segurança ontológica de alguma espécie, baseado em vários tipos de rotinas. As pessoas lidam com perigos, e os medos associados a eles, em termos das "fórmulas" emocionais e comportamentais que passam a fazer parte do seu comportamento e pensamento cotidiano. A ansiedade também difere do medo na medida em que diz respeito (inconscientemente) a ameaças percebidas à integridade do sistema de segurança do indivíduo (GIDDENS, 2002, p. 47).

Para o autor, a necessidade de uma sensação de segurança "é muito mais importante no ser humano do que os impulsos resultantes das sensações de fome ou de sede" (GIDDENS, 2002, p. 47).

Sendo o trabalho um componente central na constituição do sujeito, este vai ser um espaço onde a produção da sensação de segurança - ou não - vai abarcar diretamente a constituição de uma subjetividade de mesma espécie. Aqui reside a importância de se estudar a dimensão dos riscos invisíveis enquanto produtores diretos de sofrimento psíquico no trabalho.

\section{CONSIDERAÇÕES TRANSITÓRIAS}

Os estudos sobre a segurança do trabalho ainda concentram-se no terreno das engenharias, onde o risco é estudado enquanto uma ação que deve ser prevenida pelo uso de equipamentos de proteção individual e a partir de alguns procedimentos técnicos. A importância de se estudar o risco nas ciências sociais, em seus diferentes aspectos, faz com que possamos dar visibilidade ao tema por meio de manifestações mais sutis e até então imperceptíveis aos que trabalham junto à questão.

Assim, o risco passa a enquadrar um leque de fatores que dizem respeito à saúde e à qualidade de vida dos trabalhadores, para além do que já compunha a segurança do trabalho. Com esta nova proposta, a preocupação das empresas em garantir o bem-estar de seus funcionários também deve ser alterada no sentido de incluir no leque de estratégias de segurança ações preventivas quanto ao cuidado psicossociológico e psicológico dos seus colaboradores.

\section{REFERÊNCIAS BIBLIOGRÁFICAS}

ASSOCIAÇÃO BRASILEIRA DE NORMAS TÉCNICAS - Informação e documentação - artigo em publicação periódica científica impressa - apresentação: NBR 6022: 2003. Rio de Janeiro: ABTN, 2003.

BOURDIEU, Pierre. A dominação masculina. Rio de Janeiro: Bertrand Brasil, 2003.

GASTALDO, Édison. Goffman e as relações de poder na vida cotidiana. Rev. bras. Ci. Soc., São Paulo, v. 23, n. 68, Oct. 2008 .

GIDDENS, Anthony. Modernidade e identidade. Rio de Janeiro: Jorge Zahar, 2002. 
GOFFMAN, Erving. A representação do Eu na vida cotidiana. Petrópolis: Vozes, 1985.

HALL, Stuart. Quem precisa da identidade?. In: Silva, Tomas Tadeu da (Org.), Identidade e diferença. A perspectiva dos estudos culturais. Petrópolis: Vozes, 2000.

MARTINEZ, Maria Carmen; LATORRE, Maria do Rosário Dias de Oliveira. Saúde e capacidade para o trabalho de eletricitários do Estado de São Paulo. Ciênc. Saúde Coletiva, Rio de Janeiro, v. 13, n. 3, june, 2008.

VERONESE, Marília V; ESTEVES, Egeu G. Identidade. In. GAIGER, Luiz Inácio; HESPANHA, Pedro; CATTANI, Antonio; LAVILLE, Jean-Louis. Dicionário internacional da outra economia. Coimbra: Almedina, 2009.

Recebido em 15/04/2010 Aprovado em 08/11/2011 